\title{
Working in the Shadows
}

\section{Understanding ERP Usage as Complex Responsive Processes of Conversations in the Daily Practices of a Special Operations Force}

Christiansen, Ulrik; Kjærgaard, Annemette Leonhardt; Koss Rasmussen, Rasmus

Document Version

Final published version

Publication date:

2011

License

CC BY-NC-ND

Citation for published version (APA):

Christiansen, U., Kjærgaard, A. L., \& Koss Rasmussen, R. (2011). Working in the Shadows: Understanding ERP Usage as Complex Responsive Processes of Conversations in the Daily Practices of a Special Operations Force. Department of Operations Management, Copenhagen Business School.

Link to publication in CBS Research Portal

\section{General rights}

Copyright and moral rights for the publications made accessible in the public portal are retained by the authors and/or other copyright owners and it is a condition of accessing publications that users recognise and abide by the legal requirements associated with these rights.

\section{Take down policy}

If you believe that this document breaches copyright please contact us (research.lib@cbs.dk) providing details, and we will remove access to the work immediately and investigate your claim. 
Working in the shadows: Understanding ERP usage as complex responsive processes of conversations in the daily practices of a Special Operations Force

\section{Working paper}

Ulrik Christiansen

Department of Operations Management

Copenhagen Business School

Solbjerg Plads 3

2000 Frederiksberg

Denmark

Annemette Kjærgaard *

Department of Informatics

Copenhagen Business School

Howitzvej 60

2000 Frederiksberg

Denmark

Rasmus Koss Hartmann

Department of Operations Management

Copenhagen Business School

Solbjerg Plads 3

2000 Frederiksberg

Denmark

* Corresponding author. Tel.: +45 3815 2646; fax: +45 38152401.

E-mail addresses: amk@cbs.dk (A. Kjærgaard), 


\section{Introduction}

Organizations are met with increasing demands for being in strategic control. According to conventional managerial wisdom, clearly defined tasks, uniform processes, thorough documentation and strategic oversight are all perceived as part and parcel of making large and unwieldy organizations manageable, transparent and efficient (Johnson, Scholes, \& Whittington, 2008; Kaplan \& Norton, 2008). To live up to these demands, numerous efforts have been undertaken, including the design and implementation of management information systems. These systems, as epitomized in Enterprise Resource Planning (ERP) systems, seek to bring the organization under strategic control by creating a unified infrastructure for collecting and analyzing data from virtually all fields of organizational operations to enable planning and monitoring of activities (Kallinikos, 2006). Expectations of these systems at all levels of the organization are high as they are expected to create organizational transparency and oversight for decision making (Hanseth, Ciborra, \& Braa, 2001). In this paper, we explore how ERP systems are used and impact local practice in a specialized unit within The Danish Defense. Specifically, we ask what role SAP R $/ 3^{1}$ plays in enabling and constraining everyday local practice and the handling of complexity and uncertainty at the organizational front-line. We draw on a case study conducted in a special operations force unit within the Danish Defense, "The Frogman Corps". The case illuminates the difficulties of using ERP systems for management control in organizations experiencing complex operational conditions, including tension between centralized control and uniformity on the one hand and unpredictability and need for decentralized decision making on the other hand.

It is generally agreed that implementing and using ERP systems is a complex affair involving technical, organizational and social aspects (Boudreau \& Robey, 2005; Elbanna, 2007; Krumbholz, Galliers, Coulianos, \& Maiden, 2000; Vogt, 2000). Furthermore previous research has shown ERP systems to have numerous side-effects (Chae \& Lanzara, 2006). Academics as well as practitioners have blamed ERP for obstructing creativity and flexibility (Trott \& Hoecht, 2004), causing information overload (Kallinikos, 2009) and reducing managers to the sum of their tools (Cadili \& Whitley, 2005; Kallinikos, 2009; Tangkjær, 2005). It has also been suggested that the systems do not make the organization more controllable, but rather give the illusion of control while in fact increasing complexity and obscuring local risk handling (Hanseth, et al., 2001). Critical research on ERP systems has highlighted the de-coupling between the organizational frontline and the strategic back-office. This de-coupling has been shown to manifest itself in challenges to professional and organizational identity (Skærbæk \& Thorbjørnsen, 2007) and unpredictable reorganizations of work patterns (Scapens \& Jazayeri, 2003). Despite all these valuable insights on the organizational consequences of using ERP systems, little is still known about what causes this de-coupling and how it is related to the everyday practice and conversations about the system.

We draw on Ralph Stacey's theory of complex responsive processes to inspire our empirical observations (Stacey, 2007, 2010) and provide a lens for understanding and challenging patterns of everyday practice.

\footnotetext{
${ }^{1}$ SAP R/3 is the product name of an ERP system developed by the company SAP, originally called Systemanalyse und Programmentwicklung. The name R/3 comes from two characteristic features of the system, namely a three-tiered infrastructure (hence the " 3 ") and its real-time functioning (hence the " $R$ "). Numerous variants of the system have been created which adapt to different organizations.
} 
We pursue the research question: How do ERP systems shape and get shaped by managers' everyday conversations about organizational control?

The theory of complex responsive processes helps us to address the micro details of the local interactions in which people use systems tools of information and control. It focuses attention on how people's ongoing conversations around a system's use, as well as their use of the system, give the system meaning. The theory thereby defocuses attention on the tool itself and has primarily been empirically explored using narrative and reflexive approaches (e.g. Shaw \& Stacey, 2006; Stacey \& Griffin, 2005). Although the theory enables a perspective on complexity as a fundamental attribute of organizational life that must be handled in the everyday work practice, it is largely unused in IS studies. Understandings of complexity have been employed in IS studies (e.g. Kim \& Kaplan, 2006) and organizational studies more broadly (Crevani, Lindgren, \& Packendorff, 2010; Stacey, 2010), but Stacey's thinking on how conversational practices maintain and develop organizational action in complex and inherently unpredictable conditions has yet to be explored empirically within IS studies as it has been in studies of for example leadership in healthcare (Davidson, 2010) and public sector strategic change processes (McMillan \& Carlisle, 2007).

Applying this novel theoretical framework and understanding IS use in terms of its micro detail makes it possible to offer alternative interpretations of empirical patterns of a range of current issues in IS. First, in IS research there is a tendency to understand work-arounds and local adaptations of systems as an expression of resistance (Doolin, 2004; Ferneley \& Sobreperez, 2006; Lapointe \& Rivard, 2005). Thus, they are either seen as failures and an argument for not engaging with IS in general or as a form of resistance to change to be either overcome or praised (Thomas \& Hardy, 2011). Instead, our findings show that sidestepping of IS in the form of locally developed add-ons to the system may be a way that employees actively seek to make use of the system. This suggests that the application of a micro-level view of the use of systems in practice provides new, more nuanced understandings of front-line employees' intentions of sidestepping and locally adapting the systems (e.g. Dechow \& Mouritsen, 2005; Hanseth \& Lundberg, 2001; Maccarrone, 2000; Rom \& Rohde, 2007). Second, our study challenges the conventional understanding of control and practice as a strict dichotomy (see e.g. Davenport, 1998; Kallinikos, 2009; Poston \& Grabski, 2001). Rather, we find that in the micro level interactions, control and practice are inseparably interwoven in one process as part of the conversational life of the organization. Third, while earlier research has argued that IS increases the complexity of managing organizations (Ciborra, 2006; Hanseth \& Braa, 2001), we find that in conversational practice it is less a question of increased complexity than it is of the systems delegitimizing the existing practices of coping and living with uncertainty and unpredictability, thus bringing about an undesired unlearning of flexibility and intuition.

The paper is structured as follows. First, we present a review of previous studies of the use of ERP systems in organizations in order to position our study. Then, we provide a brief description of Ralph Stacey's theory of complex responsive processes and explain how we use the theory to explore the empirical observations. This is followed by a presentation of the research setting and the methodology used in the case study. We then present and analyze the empirical findings before discussing them in relation to earlier empirical research. Finally, we conclude with the theoretical and practical contributions of the study. 


\section{Organizational implications of using and implementing ERP}

To create an overview of the extensive literature addressing the organizational challenges of implementing ERP systems, we conducted a literature review following a concept-centric approach (Webster \& Watson, 2002). This was done to categorize the diverse body of literature dealing broadly with social and organizational issues of implementing and using ERP in general and SAP R/3 in particular, as this was the system used in the empirical case.

In the following we present four themes that emerged from our reading of the literature: "Standardizing contextualized practice", "Restructuring control, increasing uncertainty", "Complications of usage", and "Changing decision making".

\section{Standardizing contextualized practice}

One ambition in implementing ERP systems is to ensure standardized processes across the organization, thereby creating compliance to defined best practices. This creation of standardized practice has been found repeatedly in research (Davenport, 1998; Hanseth, et al., 2001; Poston \& Grabski, 2001); However, there is no consensus on what sort of behavioral change results from the imposed practice. While Caglio (2003) finds that certain personnel groups can be made to comply with pre-defined standards, Dechow and Mouritsen (2005) find that employees sidestep standard procedures and technologies in order to make their practices work. Instead of using the ERP system and following the procedures attached to it, employees employ a range of local supplements to compensate for the lack of flexibility in the standards and provide the space for local practice to work.

The very notion of process level standardization is also problematic, according to Hanseth and Braa (2001), when organizational outputs do not conform to standardization. Likewise, work by Dillard, Ruchala, and Yuthas (2005) and Kallinikos (2009) has argued that standardization quantifies the images of the organization, turning 'reality' into figures and creating an image of little practical value to local practice. Rather, local practice becomes obscured and unrecognizable in the rendition of the organization provided by the ERP system.

It is argued that ERP systems have a tendency to expand their reach, standardizing and integrating the organization further and thus hampering the potential for local practice or making even greater demands for disguising local practice as standardized process (Davenport, 1998; Hanseth \& Braa, 2001).

\section{Re-structuring control, increasing uncertainty}

It is a common expectation that ERP systems will create central oversight by giving managers constantly updated, highly detailed and easily accessible data on operations (Clemmons \& Simon, 2001; Kennerly \& Neely, 2001; Trott \& Hoecht, 2004). This means that ERP implementations often place increased demands for accountability and self-control on lower level managers, as the system enables everyone to see, plan and manage their own spending and production (Caglio, 2003; Scapens \& Jazayeri, 2003). As such, control can be both centralized and decentralized the same time with management accounting becoming everyone's responsibility (Caglio, 2003) and everyone having the opportunity to exert control as smaller organizational units become independently visible as economic entities (Quattrone \& Hopper, 2001, 2005). 
However, studies report that the practice of exercising management accounting control remains the same (see e.g. Dechow \& Mouritsen, 2005; Scapens \& Jazayeri, 2003) and very little change in, for example, budgeting practices is found (Granlund \& Malmi, 2002). Among the reasons for this lack of change, Scapens and Jazayeri (2003) point to the unpredictable and inconsistent quality of data within the ERP system, which provides insufficient grounds for controlling and decision making. Furthermore, Hanseth et al. (2001) point out that the integrated nature of the systems does not increase controllability or reduce complexity, but rather makes the organization even more ungovernable. IS, it seem, do not reduce risk, but rather introduce another element of risk to the organization's operations in the form of the system's data quality and its trustworthiness and reliability. This might also apply to ERP systems (Ciborra, 2006), which contribute to increasing unpredictability, uncertainty and drift (Chae \& Lanzara, 2006).

\section{Complications of usage}

Brynjolfsson (1993) indicates that implementing IS and ERP has very little influence on organizational effectiveness, which he describes as the 'productivity paradox'. Research by Granlund and Malmi (2002) explains this phenomenon as a result of existing practices and processes linked to previous systems 'merely' being transferred to the newly implemented one, as managers attempt to use the new system to provide the same data that the previous system provided (Scapens \& Jazayeri, 2003).This echoes the findings of Fahy and Lynch (1999) and Davenport (1998) that having data available does not lead to it being used and that no or few new performance metrics are implemented along with new IS.

In relation to the use of the system, there are also recurring findings that report of the use of tools existing outside ERP systems (Maccarrone, 2000; Rom \& Rohde, 2007) that help workers to cope with the recognized blind spots of the system (Dechow \& Mouritsen, 2005). Furthermore, findings point out that use is obstructed by the issue that no one seems to know when data is accurate enough to base decisions on or when the system actually works, because it is too complex to be understood (Scapens \& Jazayeri, 2003), exceeding the capacity of most users (Gargeya \& Brady, 2005; Granlund \& Mouritsen, 2003; Kallinikos, 2009).

These findings support the argument made by Arnold et al. (2004) that "smart systems", such as ERP systems, need smart users to be of real value. Users, they say, who do not understand the system, will not succeed in using it and cannot simply be expected to learn from experience. Similar arguments are made by Granlund and Malmi (2002) who claim that faster working practices as a result of IS are dependent entirely on the systems' users. Likewise, Van der Veeken and Wouters (2002) describe how supervisors make little use of data from accounting systems because they distrust the reliability of the data and instead base decisions on their own knowledge from daily interactions and involvement.

\section{Changing decision making}

Having data does not mean that data will be used for better decisions or decision support (Davenport, 1998; Hedberg \& Jönsson, 1978; Scapens \& Jazayeri, 2003). ERP systems are highly effective for registering transactions and collecting data, but they are not very effective as reporting tools or for decision support (Booth, Matolcsy, \& Wieder, 2000; Kaplan, 1988) and may even damage existing decision capabilities of the organization (Fahy \& Lynch, 1999). 
Although the strength of the systems is the flexibility in data provision (Spathies \& Ananiadis, 2005), the flexibility and complexity of the systems at the same time produces distrust about the system in general and the quality of the data in particular (Hanseth, et al., 2001; Kennerly \& Neely, 2001; Scapens \& Jazayeri, 2003).

What seems apparent from the reviewed literature is that while there has been considerable research done on the organizational consequences of implementing ERP, it is yet to be explored what processes govern the actual use of ERP systems and management accounting information in organizations. While previous research has found that changes in management accounting and new decision making patterns do not emerge from the use of ERP, there has been very little in-depth analysis of what processes inhibit this, including how the ERP systems frame conversations in organizations and how these conversations create organizational responses to the systems. Against this background we conducted an in-depth case study employing an alternative conceptualization of complexity and a conversation-focused understanding of micro-level action with the aim of explaining what people do in response to the ERP systems which are part of their daily work practice.

Before we present our empirical case and our analysis of it, we introduce the theoretical lens of organizations as complex responsive processes.

\section{Understanding ERP usage as complex responsive processes}

Adopting the theory of complex responsive processes to understand organizations means, at its most fundamental level, to focus attention on the conversational life of the organization - "It is in communicative interaction, in conversations with each other," Stacey argues, "that humans accomplish whatever it is they accomplish. Organization is conversation and organization and strategy emerge through conversation" (Stacey, 2007, p. 270). This means that when seeking to understand what goes on in organizations, we should stop paying attention to elements, individual actors, organizational design and technologies and instead look to the everyday conversations of people and how they enable and constrain new conversations and actions.

Based on a conversational focus inspired by Mead, Stacey argues that people are continually involved in responsive processes of communicating with each other. The notion of responsiveness draws on Mead's concept of the generalized other and refers to how conversations are not straight-forward matters of delivering an intended message. Rather, people communicate based on their intentions and desires as well as their understanding of other people and their intentions in a process of constant negotiation and mutual adjustment. We are constantly trying to both understand the people we communicate with and adapting our communication to how they respond and to what we think, they are thinking, feeling, intending and to what others not involved in the conversation (both specific others and generalized others) may think. In this way, people and their intentions constantly shape and are shaped by those of others: "A single individual does not simply 'have' an intention. Rather the intention an individual expresses has emerged in the conversational interaction with others. Intention and choice are not lonely acts but themes organized by and organizing relationships at the same time" (Stacey, 2007, p. 281).

By making conversations the starting point for understanding organizations and conceptualizing them in these responsive terms Stacey points to the understanding that organizations are complex, i.e. both beyond 
the control of any individual or group and unpredictable. Because all anyone can ever do is engage in conversations, no one, no matter how powerful, is able to control the outcomes of their conversations: "all are participants and none of them can get outside the conversation, observe it or control it" (Stacey, 2007, p. 278) and "no one can be 'in control' of the interplay of desires and intentions or even fully understand that interplay" (Stacey, 2007, p. 303). While this does not mean that action is futile, it does mean that if one wants to change organizations, one should focus on changing the conversations in them. Potentially, "everything that everyone does, or does not do, matters in what is always local conversational interaction" (Stacey, 2007, p. 281). So, while there are no certain outcomes and action is "restricted" to communicative interaction, the perspective of complex responsive processes also implies that all actions have the potential for influencing what we perceive as the unity of the organization.

In seeking to understand conversations in organizations, Stacey points to the importance of examining the conversational themes organizing communicative interaction, i.e. the thematic patterning of everyday conversations. Here, it becomes important to understand what gets talked about, how and by whom. While some issues are legitimate themes and are openly talked about, because people feel and believe that others feel they are legitimate, others are excluded from legitimate conversations and confined to unofficial conversations and gossip. These latter themes are what Stacey calls shadow themes. The dynamics of conversational inclusion and exclusion, i.e. whether something becomes a legitimate or shadow theme, depends on the interplay of ideology and power relations in the organization.

In thinking about power relations, Stacey posits that "the top executives have more power than others, that is, a greater capacity to instruct, persuade or even force others to do what they want... Small groups of very powerful people at the top of an organization allocate resources and in so doing both enable and constrain other members of the organization... they legitimize some actions and not others" (Stacey, 2007, p. 322). "The basis of power is need, so that when we need others more than they need us... then they have more power over us than we do over them" (Stacey, 2007, p. 353). This makes power a matter of possessing resources that make it possible as well as impossible for others to act. In this way power can come to influence conversations directly (i.e. through the threat of limiting resources) or indirectly, because the responsive nature of conversations means that people are constantly communicating based on their expectations of the other (i.e. trying to understand what actions may lead to threats to their available resources).

Shaping and shaped by power relations, "ideology can be thought of in paradoxical terms as the simultaneous voluntary compulsion of value and the obligatory restriction of norm" (Stacey, 2007, p. 359), thereby reflecting the identity of people as they make sense of who they are and what it is right to do and not do. It "provides criteria for choosing one action rather than another - decision making - and it serves as the unconscious basis of power relations" (ibid) and may be both official and unofficial, i.e. perceived as legitimate and shared or illegitimate, marginal and unacceptable to those in power. "The distinction between legitimate and shadow themes", Stacey argues, "is intimately related to ideology, which can be either official or unofficial" (Stacey, 2007, p. 379). He suggests that it is ideology that legitimizes a conversation and in particular, it is the ideology that sustains current power relations that makes conversation feel natural, acceptable and safe and thereby legitimate "despite the official ideology, people may act in ways consistent with unofficial ideologies, even though they cannot talk about how their actions are justified by their unofficial ideologies" (Ibid). When people engage in shadow conversations, they do so 
secretly but also on the basis of some unofficial ideology that makes it feel natural and justifiable to talk as they do (Ibid).

Understanding the conversations in these terms, however, means understanding them as dynamic - what constitutes legitimate and shadow themes changes depending on the conversation and who participates in it. Even then, it is constantly shaped by how people perceive larger patterns in the organization. Based on the expectations towards one person, it may feel legitimate to talk openly about certain issues, while expectations towards another (based perhaps on earlier conversations or that person's position and power) may exclude them. Having participated in or heard of other conversations, likewise, may create inclusion or exclusion for particular themes. It is this perspective that we will now seek to apply to understanding IS use in our case organization.

\section{Method and empirical setting}

The case organization, the Frogman Corps of the Danish Navy (hereafter referred to as FMC), was chosen as an extreme case (Yin, 2009) to study the ambiguity of control: even as organizational reality is complex and unpredictable, efforts are made to control and document it. From Stacey's perspective of understanding how complexity is handled and unpredictability lived with, the role of a large-scale ERP system as a means of control seems particularly interesting for how it enables and constrains certain aspects of practice in an organization working with high-risk operations and unpredictable circumstances. As is the nature of extreme cases, the observed phenomena in the case organization may yield valuable and relevant insights into organizations operating in less extreme versions of the ambiguity experienced here (Flyvbjerg, 2001; Yin, 2009).

\section{Empirical setting}

The FMC is a special operations unit in the Danish Navy similar to the US Navy SEALs although substantially smaller. The workforce consists of nearly 300 employees out of a total of approximately 27,000 employees working in the Danish Defense. The FMC has recently been involved in both Iraq, Afghanistan and in Somalia and its primary tasks are counter-terrorist work involving opposed boarding on ships, VIP protection and apprehending high value targets.

The FMC started using SAP in 1998 when the Danish Defense implemented the system throughout its organization. The primary purpose of implementing SAP was to meet the accounting standards of the National Audit Office of Denmark (Statsrevisoratet, 1999). The initial implementation took place in 1999 and our studies have therefore been post-adaptive (Jasperson, Carter, \& Zmud, 2005).The FMC are currently using the following modules in SAP: SAP HR (human resource), SAP CO (controlling) and SAP MM (logistics). SAP is used at all levels of the organization, ranging from the organizational frontline, where the soldiers use SAP for keeping track of equipment, education, work hours and travel compensation, to the back office functions where SAP is used for management information to comply with budgetary demands within the Danish Defense.

The implementation of SAP in the Danish Defense is one of the most extensive SAP implementations across the public and private sectors in Denmark (Skærbæk, 2009) and the use of the system has posed a series of problems to the Danish Defense which have been discussed continuously within the Danish Defense and 
the National Audit Office of Denmark (Statsrevisoratet, 2002) but also publicly by politicians and in the media (Skærbæk \& Thorbjørnsen, 2007). Criticism has mainly been raised of insufficient focus on using the system by higher echelons of command, insufficient education of system users and insufficient quality of data (Rigsrevisionen, 2005; Thorbjørnsen, 2007; Thorbjørnsen \& Skærbæk, 2007). This has resulted in continuous modifications of the original system and the procedures for using it.

\section{Data collection and access}

The case is based on empirical data collected through observations, interviews and documents by one of the authors who, prior to enrollment for graduate studies, served as a platoon commander in the FMC and had five years of experience working with SAP in the case organization. Furthermore, the author's position in the FMC gave virtually unrestricted access to all levels of the organization and very direct participation in conversations and access to a range of documents relevant for this study.

Additionally, to explore the full potential of the case and to strengthen the empirical foundation of our findings, we collected empirical data from several sources including participant observation and informal conversations and open and semi-structured interviews with selected managers, all collected from March to June 2007.

A four months period of participant observation was conducted to study the experience of FMC leaders working with SAP in their everyday practice. The focus was a group of leaders spanning platoon commanders $^{2}$, staff officers ${ }^{3}$ and the executive commander of the FMC - all formally educated in the SAP modules they were using. The participant observation was conducted as daily interactions amongst the officers as well as other personnel (Bryman \& Bell, 2003). We attended meetings amongst the managers and our focus were how SAP appeared in conversations, how it was described and what it was associated with. Furthermore, attention was paid to how people talked about the system and how they used data extracted from it. During the period of participant observation, we engaged in informal conversations to further explore the above mentioned points of interest. The observations were recorded in field notes within a few hours of the experience as the conversations typically took place while walking with the interviewees between classrooms, on the running track or in the lunch room.

We conducted 25 open interviews (Kvale, 1996) with the officers, typically following meetings. These interviews were exploratory, covering a wide variety of topics related to the respondents' use of data from SAP and how SAP was talked about in daily practices. Particularly, we asked for narratives describing situated use of or discussions about the system. After these initial interviews, we conducted 11 semistructured interviews exploring in greater detail the conversational themes surrounding SAP and repetitive patterns of description and use. Each interview lasted from 30 minutes to two hours and was taped and transcribed in full. The transcriptions were sent to the interviewees to ensure accuracy. On a few occasions, respondents wanted to elaborate a point or provide a better explanation of an issue, in which case followup interviews were conducted.

Various documents related to the implementation and use of the ERP system were collected to gain insight into the decisions about the system's functionality, expectations of its relevance and use and the problems

\footnotetext{
${ }^{2}$ Platoon commanders are often ranked as first lieutenants and have command of approximately 20 soldiers.

${ }^{3}$ Staff officers serve in support functions like administration, training and logistics and rank from captains to majors.
} 
encountered. These documents formed a contextual understanding of the system in relation to the organization and provided valuable information about management's considerations.

As background data, we used one of the authors' personal notes collected from 1999 to 2005 and documents including e-mails, minutes from selected meetings, strategy reports and decision summaries collected between 2001 and 2005. The personal notes were re-written in narrative form prior to initiating the present study, approximating Stacey's concept of reflective management narratives (Stacey, 2007).

Drawing on Stacey we focused on patterns of conversation and looked for shadow themes that run contrary to what was experienced as formally correct or oppositional. We also looked at how individuals talked about taking responsibility for the use of the ERP system and how they experienced using the system to deal with uncertainty and control. Finally, we asked operators what problems they experienced with using the system and whether these problems were acknowledged by the organization.

\section{Data analysis}

We analyzed the data, following the guidance of Miles and Huberman (1994) and Strauss and Corbin (1998), travelling back and forth between the data and the emerging categories for the usage of SAP.

The analysis was twofold: First we analyzed and conceptualized the data, which had been collected from the field study and second we related the constructs to the findings from the literature review in order to challenge our findings. We began the analysis by naming and conceptualizing the empirical data, focusing on inspecting the various data sources to look for statements, actions and interactions to create an understanding of how SAP was talked about, what features of the system were emphasized, which were ignored and how people experienced others' use of the system. Here, we looked for descriptions of recurrent conversational themes and for when these were described as legitimate and shadow themes respectively (Stacey, 2007). In this process, the various documents and personal notes were used to strengthen our background understanding of the context of the interviews and observations.

Further, we related identified conversational themes to the empirical material to identify how they were connected with expectations to the system, use situations and what people experienced as the effects of the system. Finally, we compared the patterns to our findings from the literature review in order to focus on the most relevant and contributing empirical findings (Locke, 2001).

The resulting categories were presented at a management meeting at $\mathrm{FMC}$ to ensure that they were in accordance with our informants' experiences. This was done on two occasions to ensure that anyone who took part in the research got the opportunity to comment on our findings. The feed-back from these meetings was used to further analyze the findings. 


\section{Empirical analysis and discussion}

The empirical findings are clustered into three categories: 'Complying with the system', 'Sidestepping the system' and 'Adapting to the system'. In the following three sections, each category is elaborated in more detail and related to the themes identified in the literature review. Moreover we will show the tension between legitimate conversational themes and shadow conversational themes in each category and how this tension is organized through power relations and ideology.

\section{Complying with the system - striving for legitimacy}

In the FMC, SAP was generally described as something that ought to deliver gains in administrative productivity and make processes easier, thus reflecting a general tendency in ERP implementations (Davenport, 1998; Scapens \& Jazayeri, 2003). Following the heavy investments in development and implementation of the system throughout the Danish Defense (Skærbæk, 2009) and the repeated calls for using it from higher levels of command, the officers describe how they expect SAP to be a very helpful tool. As the commanding officer says:

"We do not doubt that SAP will help us. We just need to break the code to using the system."

In this way, the officer echoes the public transcript of the SAP implementation from central command, which focuses on the suitability of the system and its potential to simplify and ease work processes. This reflects the official premise for the conversations between FMC officers and the superior organizations that SAP is the right system for the organization, that it has been implemented correctly and generally functions as intended. In this understanding, using SAP in management practice and complying with the system is the sign of a competent organization and competent management.

Conversational themes about how SAP should integrate financial, logistical and personnel related data are legitimate in that these expectations are talked about openly and the officers repeatedly mention their expectations of what the system ought to do as well as the changes that it makes possible. One officer describes these changes as effecting decision making:

"We are moving away from making decisions on gut feelings to using facts."

In this way, the officers seem to exhibit a greater loyalty towards the system and a greater willingness to using it than seen in previous research (e.g. van der Veeken \& Wouters, 2002), although the skepticism towards data quality and reliability is experienced (as also echoed in Hanseth, et al., 2001; Kennerly \& Neely, 2001; Scapens \& Jazayeri, 2003) and openly talked about. However, contrary to previous findings, the legitimate explanation for these problems is related not to the system itself but to the users, as expressed by an administration officer saying:

"We need to fuel the system with better data, before we can use it for decision making" In demonstrating their desire to work more and better with the system, the officers emphasize how everyone is educated to use the system and how still more civilian employees are hired in the administrative functions to bring in greater user competence. 
In the less official conversations on complying with and using the system, these themes are given an additional dimension that is less readily talked about and not repeated to superior levels of command. Relating to the use of the system, the officers talk about the need to comply with the system in order to present themselves and their organization as 'capable' and 'professional'. In these conversations we found that the officers tried to show their compliance with the system and, thus, adhere to the official ideology and power relating of appearing credible and competent, which is a precondition for maintaining the adequate funding of their unit as well as its freedom from close supervision and control. As such, a strong shadow theme exists concerning the loss of freedom and military operational ability that may result from not following the public transcript of SAP's possibilities and usefulness. The power of superior organizations to reduce funding or increase managerial control over the organization thus forces the officers to demonstrate their compliance with the system.

In this shadow theme of complying with the system, we see an interesting interplay between two ideologies, namely that of SAP's usefulness and one of maintaining operational independence and a space of the uniqueness of the FMC. This unofficial ideology, grounded in an understanding of self-sufficiency and self-reliance crucial to the operational usefulness of the Frogmen which is regularly talked about as a defining characteristic of the unit, is thus talked about as only being possible through maintaining an outward appearance of compliance. Paradoxically, the officers thus experience that the only way they can remain independent is by complying. The use of SAP thus becomes a means of as well as an arena for exercising power in relation to the superior organizations. We observed many lunch breaks spent talking about how demonstrating individual competence in the use of SAP was essential for individual career advancement. Resisting to use SAP or refusing to base decisions on it was in these conversations talked about as disqualifying one from further promotion (see also Skærbæk \& Thorbjørnsen, 2007).

However, this perceived need to use and comply with the system, also posed a challenge for the officers in the FMC, because many soldiers in the FMC perceive SAP as both problematic and bureaucratic. One of the officers describes how:

"... most parts of the corps, who do not use it [SAP] in their everyday practice, perceive it [SAP] as a constraint, because every time we have a delay or something goes wrong in our department [the administration office], it is always related somehow to the system [SAP]."

In these conversations using SAP becomes a question of maintaining legitimacy in relation to the operative sphere in the FMC. Instead of compliance being connected to the attempts to maintain independence as a unit, in these conversations compliance and the attempts to make use of the system are linked to an ideology of managerialism. As such, SAP becomes synonymous with the exercising of management control and resource-related decision making, which again becomes linked to an ideology of managerialism and distinct from a military operational ideology. This has the double effect of obscuring the managerial aspects of operational practices (i.e. questions of resource scarcity and allocation) and making it possible to blame all problems and inconveniences on SAP. In these conversations, the officers linked many burdens and problems to SAP. This is illustrated by this statement by an officer who describes how data must be collected prior to deployment for registration in SAP: 
"Just before a deployment, when we ought to focus on the forthcoming operation, we still spend time manually going from office to office [with print outs of individual equipment lists], just to make sure everybody's got everything for the operation... this is really a burden for everyone in the unit".

This shows how a fundamentally operational task of ensuring that everyone is functionally equipped becomes administrative and linked to the need for compliance with an overly bureaucratic structure in SAP.

\section{Sidestepping the system - unexpected patterns of inclusion for management}

As a consequence of the difficulties of using SAP, the officers in the FMC describe the need for sidestepping the system to carry out their work. While this sidestepping follows the need to publicly comply with the system, it is a clear shadow theme in relation to the Admiral Danish Fleet, where officers in FMC speak openly about the difficulties of using the system amongst one another and how they instead use Excel spreadsheets to either extract or manipulate data in order to make it fit their information needs or maintain their own systems for control. Similar to what Kennerly and Neely (2001) found, the officers describe SAP to be notoriously difficult to use in practice, as mentioned by an administration officer:

"Although I really spend time trying to solve a problem in SAP, I usually end up doing everything in the PC's Excel program."

As such, the officers bypass SAP entirely when they find it too difficult to use or use it in concert with systems they themselves develop in Excel to make data understandable and usable (see also Dechow \& Mouritsen, 2005; Fahy \& Millea, 2001; Granlund \& Malmi, 2002; Maccarrone, 2000; Rom \& Rohde, 2007).

This bypassing of the system is openly accepted in the $\mathrm{FMC}$, because it is also generally accepted to talk about how SAP easily becomes an obstruction that slows down momentum in dealing with problems. This reflects Ortmann's (2010) finding that a standardized system can become obstructive in local practices if not adapted. One example of this relates to SAP'S HR module, in which all employee qualifications are listed. However, the standardized categories that the system makes available do not fit the specialized education and training that the soldiers receive from other special operation forces outside Denmark. This is explained by the operations officer as an example of why the system is rarely used for planning, as also mentioned by Dechow and Mouritsen (2005):

"You cannot use the Qs [register of qualifications] to determine if the soldiers are qualified for the assignment....all you can see is if they have a driver's license or not".

Due to this "blind spot" of the system (Dechow \& Mouritsen, 2005), the conversations about which units in FMC are qualified to fulfill which tasks become based on themes other than ones involving SAP. Rather, these conversations are based on local knowledge gathered informally from the on-going conversations between the officers.

Another reason why the officers intentionally sidestep the system and maintain their own spreadsheets relates to the access granted by the system: when soldiers are deployed in operations controlled by other units (i.e. the command staff in a given deployment comes from a particular unit, frequently from Army regiments), the access to their personnel files is transferred from the FMC to the controlling unit. When this 
happens, no one in the FMC can get any information about "their" soldiers, which is a concern for the operation officer:

"I hope it never happens, but if one of the guys gets injured...there is no way I can get the access to his personal information, so that I can contact his relatives and tell them what is going on".

This leads the officer to maintain a parallel system containing these details of all personnel, which must be updated every time the personnel data in SAP is updated or changed. This extra administrative work is, however, reflective of the social needs and ideology of the FMC and officers who prioritize to maintain the system anyway.

Another problem of standardization can be seen in relation to the logistics module, where many of the items of equipment used by the FMC are not listed or if they are, they are referred to in very different terms from what is used in practice. In some cases this happens because certain items are procured locally and not through the Danish Defense Acquisition and Logistics Center and therefore do not show up in the centrally updated inventory lists. In other cases it is caused by the Danish Defense Acquisition and Logistics Center who acquire the items and provide them with a name unfamiliar to the FMC. One example of this phenomenon is a soldier who searched for a certain type of helmet but found that it simply did not exist in the system. As a consequence he could not order a new one to replace the one he had broken in training. As it turned out, the helmet was referred to as Fairwind in SAP and not Protec as it was referred to by the soldiers. Protec is written on the side of helmet while Fairwind is the company who produces the helmet. A second example is that certain items are not visible in the system, because of the way they are classified which makes them 'invisible' in the system. In this situation, no central budgetary measures are taken to secure the maintenance of this equipment. As put by a logistics officer:

"If it is not in the system, Central Command will not recognize its existence...but they still want us to do the job".

For the officers in the FMC, the examples described above contribute to the experience of frequently encountering the limits of the system and the disappointment this brings. As an administrative officer says:

"We have SAP which should support all our working processes and then we end up spending time on addons just to get the job done."

This frustration leads to the open discussion of the problems of using SAP. Furthermore it fuels the conversations about how it is legitimate to sidestep the system, although many of the officers also talk about the sidestepping as problematic. While the problems of using SAP has been a shadow theme, the repeated frustrations lead the officers to talk openly amongst peers about the sidestepping and problems, while it still remains a shadow theme in their conversations with the soldiers and the superior organization. This pattern of conversations reflects a tendency to talk about sidestepping as a failure of the officers to use the system, because the expectation is that SAP should be comprehensive enough to make such sidestepping unnecessary.

These patterns of conversation, however, disguise the value of the sidestepping to the officers and their superiors. In the officers' ideology sidestepping is illegitimate and it is hardly ever talked about how sidestepping actually makes it possible for the officers to control things and cope with uncertainty by using 
locally developed systems independently of SAP or 'translating' data from SAP into relevant information which makes it possible for the officers to monitor and control a range of things that SAP itself does not make possible. Instead of seeing their own Excel systems as part of the effort to use SAP, they talk about it as a failure of themselves instead of the system, although they do in fact use the system as often as they can. The disappointment is expressed by an officer:

"[y]ou get the feeling that you're constantly typing data into the system without ever using it"

This conceals the fact that a lot of data is being used in the officers' everyday practice. It is used and plays a role in conversations but does so in unexpected ways and is therefore not recognized as legitimate due to the official ideology about the system.

\section{Adapting the system - artful resistance to include ideology}

Although much of the discontent surrounding the use of SAP is organized by shadow themes in the conversations, certain forms of resistance towards the system are articulated as legitimate themes both within the FMC and in conversations with superiors. Particularly, the officers work on and talk about generating a novel control and reporting metric called the readiness code.

The readiness code, as talked about by the officers, should ideally indicate whether an FMC unit is deployable, i.e. fully functionally equipped and at the sufficient level of physical and technical training and free from any injuries. For the officers and the Admiral Danish Fleet, the readiness code should be readable at any time (to show the current level of readiness) and in hindsight (to evaluate how many units have been at what level of readiness over a given period of time). As the officers talk about it, the readiness code should ideally be expressed as a traffic light with a "green-yellow-red" indicator, with green showing complete readiness, yellow some short-comings and red not-ready. It should be an indicator drawing together data from SAP's logistics and HR modules, showing, respectively, the availability and state-ofrepair of the required equipment and whether individual soldiers within a unit are up to date with various specified forms of training, comply with physical demands and are uninjured. Green readiness would be shown when all conditions for readiness are met, while yellow and red would be displayed whenever certain conditions are not met.

The effort to develop this novel metric reflects several phenomena rooted in the conversational patterns experienced by the officers of the FMC. For one, it reflects an attempt to adapt the system in a way that is different from the attempts to comply as well as the practices of sidestepping. Rather than feeling compelled to comply by system standards, it shows the officers trying to change how the system is worked with. In this way, the work to develop the readiness code is an act of resistance towards the system: the officers attempt to create the possibility of inclusion for a new performance metric that, they feel, says more about their performance than the current controls, which are more financial in character. In this way, the resistance towards the system is fundamentally reflective of the officers' ideology. At the same time the conversations about the readiness code supports the officers' understanding of who they are and what they are actually doing. Finally it is an attempt to create an opportunity for changing the conversations about control that are currently locked in accounting terms. As such the officers are effectively attempting to change how quality or performance can be talked about to include indicators fundamentally more 
reflective of their professional identities and ideologies. According to the officers, being deployable and maintaining a high degree of operational readiness, is more reflective of "quality output".

In itself, SAP has not led to the introduction of decidedly new metrics (as shown by Granlund \& Malmi, 2002) but we do see a considerable desire to develop them. The work conducted on the readiness code reflects the officers desire both to use system data that they know is available in the system, having experienced the frustration of typing it in, and to use it actively for managing and reporting performance. It also reflects a considerable effort to learn to use the system by drawing together data in self-designed reports. While the readiness code is both a resistance towards the system and the way it operates, it is a resistance that indicates a considerable attempt and willingness to learn. While the attempts to develop the readiness code are talked about openly with superiors, the superiors do not provide any technical support in developing them.

The effort, however, is also reflective of the power relation between the FMC and the superior organization regarding conversations about the requirement for basing decisions on systems data. If the officers did not have to use the system, the readiness code might simply be reported on a regular basis by direct reports from unit commanders based on their up-to-date knowledge of their soldiers.

\section{Contributions and Conclusion}

We conclude this paper by outlining how the use of Stacey's theory of complex responsive processes contributes with new knowledge about the use of ERP systems in organizations and what implications this has for research and practice.

The main contribution of the study is the application of a micro perspective on the use of ERP that shows how the meaning of a systems tool does not lie in the tool itself but in how people use it as well as how the conversations around its use has implications for how it is actually used.

First, the empirical findings clearly show that there is a widespread use of add-ons or self-developed spreadsheets that supplement the use of the system tool. While add-ons and sidestepping can, and often should, be viewed as resistance towards large-scale ERP systems, our study suggests that they could rightly also be seen as an expression of a willingness to exert managerial control beyond what is possible with the ERP system. Both legitimate and shadow themes are an important part of how ERP systems are localized and adapted to practice. And as such these conversational themes are a part of organizational life and a way of trying to cope with anxiety and uncertainty when implementing new technologies in organizations. In this way conversational patterns enable what is being done and at the same time constrain what is being done as power relating (Stacey, 2007). Add-ons can thus be viewed as a positive contribution to the organization's control practices and not as an act of resistance as it is often portrayed (Dechow \& Mouritsen, 2005; Doolin, 2004; Ferneley \& Sobreperez, 2006; Lapointe \& Rivard, 2005). This is supported by our findings which show that while many of the officers publicly support the system they still spent time developing their own add-ons and sub-systems instead of learning how to use the system as originally intended. If management seek to address the sidestepping of the system and focus on the locally developed add-ons and side-stepping processes as a way for employees to make use of the system rather than to avoid it, they will enable a more nuanced view of the system and enable local adaptations which again might benefit the use of the system in practice. 
Second, our study contributes to emphasize the need for continuous conversation about the use of the system in its current form. We did not observe anyone discussing the potential of SAP in its current form to contribute to everyday practice, just as the system only rarely was used in forecasting and planning work. As such, a theme concerning exemplary use of the system never emerged to challenge the perception that the current form of the system was usable. This may be explained by the system having been in the organization for many years when we studied it, meaning that the people we talked to may have attempted earlier but have now abandoned the effort. Nevertheless we found that there were numerous conversations about what the officers were interested in being able to control and analyze - they just did not focus on how SAP might contribute and SAP in its current form was never linked to desired futures. Instead, solutions were always looked for in other tools. An interesting finding in our study is that the optimism concerning SAP and the stated willingness to work with the system seem relatively high: the interviewed officers express a desire to work with the system, yet find that the barrier to doing so is a combination of their own inability to use the system and its complexity. The same seems to be the case in the attempt to develop new reporting metrics (e.g. a readiness code) in the system. This indicates, and is supported by the extreme case nature of the organization studied, that the dichotomous conceptualization of practice as antagonistically opposed to control (as seen in Skærbæk \& Thorbjørnsen, 2007) may be overstating the dilemma and disregarding the ability and ambition of practitioners to control and be controlled through ERP systems. Based on the findings that control and practice are inseparably interwoven in one process as part of the micro level interactions and the conversational life of the organization, we suggest management by opening conversations about the everyday use of the system tool can reduce the dichotomy between control and operational practice.

Third, although our study contributes to challenging the dichotomy between control and practice and points to the potential for a more nuanced understanding of the use of the system, it also shows an interesting pattern concerning the unlearning of the ability to cope with uncertainty and to base decisions on professional intuition. Our finding that the ERP system obstructs the ability to cope with uncertainty contributes to explain the findings by Hanseth et al. (2001) that systems obscure local risk handling and creates side effects. While Scapens and Jazayeri (2003) described how accountants perceive their professionalism challenged by ERP systems, our study shows the system impacts more broadly. Recognizing the need for the adaptability, momentum and fast-pace change in modern organizations, this particular effect of ERP systems is relevant to explore in further detail.

To sum up the implications for practice that our study shows from using Stacy's perspective on the local organizations of organizational life, we first of all recommend that local managers try to create opportunities to discuss the contradiction between publicly agreeing that the system has potential while privately not using it. By opening up for a discussion of the potential vs. the actual use of the system, these conversations might support a local understanding of how the system can be used differently in the local context - leading to an enhanced quality of conversational life (Stacey, 2007). Secondly when implementing IS technologies such as ERP systems leaders should be open for local deviance in the form of noncompliance with legitimate and official conversational themes. The use of shadow themes in local conversations such as conversations about add-ons and sub-systems might in fact be an expression of a wish to work with the system and trying to incorporate the system as a part of a particular practice. Furthermore such local interaction and conversations about the system might lead to useful insights in 
terms of unofficial innovations which could lead to actually getting the system to work locally and become a part of practice (Stacey, 2007).

Finally our findings suggest that attention should be paid to the role of conversations about the system and suggest that managers can act in the complex realities of ERP systems to support their use by continually acting and communicating with the intention of including the system in everyday conversations, taking seriously the experiences of others in working with it. To these ends, we find Stacey's perspectives to offer alternative and helpful explanations useful to focus attention on local interaction rather than simply on abstract systems. As such, this perspective could contribute to new insights for further studies about the local use of IS systems in the future.

In conclusion, we have conducted a case study of the dilemmas faced by organizations using ERP systems between the need for centralized control and inevitable uniqueness and unpredictability of local practice. Using Stacey's theory of complex responsive processes as a lens for inquiring into local interaction through conversations (Stacey, 2007, 2010; Stacey, Griffin, \& Shaw, 2000), we have been able to study not only how ERP systems are used post-adoptively, but also understand this use as resulting from responsive and iterative conversational patterns. Although the design of ERP systems constrain and enable usage in certain ways, leading to similar experiences of working with the system, the ways the systems are projected in conversations shape the social use of the system, including decision making. As such, 'use' of the system is highly influenced by the local conversations about the system and, based on these conversations, how people act as well as react to the system.

\section{References}

Arnold, V., Collier, P. A., Leech, S. A., \& Sutton, S. G. (2004). Impact of intelligent decision aids on expert and novice decision-makers' judgements. Account Finance, 44(1), 1-26.

Booth, P., Matolcsy, Z., \& Wieder, B. (2000). The impacts of enterprise resource planning systems on accounting practice - the australian experience. Australian Accounting Review, 10(2), 4-18.

Boudreau, M.-C., \& Robey, D. (2005). Enacting integrated information technology: A human agency perspective. Organization Science, 16(1), 3-18.

Bryman, A., \& Bell, E. (2003). Business research methods. Oxford: Oxford University Press.

Brynjolfsson, E. (1993). The productivity paradox of information technology. Communication of the ACM, 36(12), 67-77.

Cadili, S., \& Whitley, E. A. (2005). On the interpretive flexibility of hosted erp systems Working Paper Series, No. 131: Department of Information Systems, The London School of Economics and Political Science, London.

Caglio, A. (2003). Enterprise resource planning systems and accountants: Towards hybridization? European Accounting Review, 12(1), 123-153.

Chae, B., \& Lanzara, G. F. (2006). Self-destructive dynamics in large-scale technochange and some ways of counteracting it. Information, Technology \& People, 19(1), 74-97.

Ciborra, C. U. (2006). Imbrication of representations: Risk and digital technologies. Journal of Management Studies, 43(6), 1339 - 1356.

Clemmons, S., \& Simon, S. J. (2001). Control and coordination in global erp configuration. Business process management journal, 7(3), 205-215. 
Crevani, L., Lindgren, M., \& Packendorff, J. (2010). Leadership, not leaders: On the study of leadership as practices and interactions. Scandinavian Journal of Management, 26, 77-86.

Davenport, T. H. (1998). Putting the enterprise into the enterprise system. Harvard Business Review., 76(4), 121-131.

Davidson, S. J. (2010). Complex responsive processes: A new lens for leadership in twenty-first-century healthcare. Nursing Forum, 45(2), 108-117.

Dechow, N., \& Mouritsen, J. (2005). Enterprise resource planning systems, management control and the quest for integration. Accounting, Organizations and society, 30(7-8), 691-733.

Dillard, J. F., Ruchala, L., \& Yuthas, K. (2005). Enterprise resource planning systems: A physical manifestation of administrative evil. International Journal of Accounting Information Systems, 9(1), 21-42.

Doolin, B. (2004). Power and resistance in the implementation of a medical management information system. Information Systems Journal, 14(4), 343-362.

Elbanna, A. R. (2007). Implementing an integrated system in a socially dis-integrated enterprise: A critical view of erp enabled integration. Information, Technology \& People, 20(2), 121-139.

Fahy, M. J., \& Lynch, R. (1999). Enterprise resource planning (erp) systems and strategic management accounting. Paper presented at the 22nd Annual Congress of European Accounting Association, Bordeaux.

Fahy, M. J., \& Millea, I. (2001). Strategic enterprise management systems: Some empirical evidence from the $u k$ and ireland. London: CIMA.

Ferneley, E. H., \& Sobreperez, P. (2006). Resist, comply or work-around? An examination of different facets of user engagements with information systems. European Journal of Information Systems, 15(4), 345-356.

Flyvbjerg, B. (2001). Making social science matter: Why social inquiry fails and how it can succeed again. Cambridge: Cambridge University Press.

Gargeya, V. B., \& Brady, C. (2005). Success and failure factors in adopting sap in erp system implementation. Business Process Management Journal, 11(5), 501-516.

Granlund, M., \& Malmi, T. (2002). Moderate impact of erps on management accounting: A lag or permanent outcome? Management Accounting Research, 13(3), 299-321.

Granlund, M., \& Mouritsen, J. (2003). Problematizing the relationship between management control and information technology. European Accounting Review, 12, 77-83.

Hanseth, O., \& Braa, K. (2001). Hunting for the treasure at the end of the rainbow: Standardizing corporate it infrastructure. Computer Supporter Cooperative Work, 10(3-4), 261-292.

Hanseth, O., Ciborra, C. U., \& Braa, K. (2001). The control devolution: Erp and the side effects of globalisation. Advances in Information Systems, 32(4), 34-46.

Hanseth, O., \& Lundberg, N. (2001). Designing work oriented infrastructures. Computer Supported Cooperative Work, 10, 347-372.

Hedberg, B., \& Jönsson, S. (1978). Designing semi-confusing information systems for organizations in changing environments. Accounting, Organizations and Society, 3(1), 47-64

Jasperson, J., Carter, P. E., \& Zmud, R. W. (2005). A comprehensive conceptualization of post-adoptive behaviors associated with information technology enabled work systems. Management of Information Systems Quarterly, 29(3), 525-557.

Johnson, G., Scholes, K., \& Whittington, R. (2008). Exploring corporate strategy: Text and cases (8th ed.). London: Prentice Hall.

Kallinikos, J. (2006). Information out of information: On the self-referential dynamics of informatiomn growth. Information Technology \& People, 19(1), 98-115.

Kallinikos, J. (2009). On the computational rendition of reality: Artefacts and human agency. Organization, 16(2), 183-202.

Kaplan, R. S. (1988). One cost system isn't enough. Harvard Business Review, 66(1), 61-66. 
Kaplan, R. S., \& Norton, D. P. (2008). The execution premium: Linking strategy to operations for competitive advantage: Harvard Business Press.

Kennerly, M., \& Neely, A. (2001). Enterprise resource planning: Analysing the impact. Journal of Integrated Manufacturing Systems, 12(2), 103-113.

Kim, R. M., \& Kaplan, S. M. (2006). Interpreting socio-technical co-evolution: Applying complex adaptive systems to is engagement. Information Technology \& People, 19(1), 35-54.

Krumbholz, M., Galliers, J., Coulianos, N., \& Maiden, N. A. M. (2000). Implementing enterprise resource planning packages in different corporate and national cultures. Journal of Information Technology, 15(4), 267-279.

Kvale, S. (1996). Interviews: An introduction to qualitative research interviewing: Sage.

Lapointe, L., \& Rivard, S. (2005). A multilevel model of resistance to information technology implementation. Management of Information Systems Quarterly, 29(3), 461-491.

Locke, K. (2001). Grounded theory in management research. London: Sage.

Maccarrone, P. (2000). The impact of erps on management accounting and control systems and the changing role of controllers. Paper presented at the 23rd Annual Congress of the European Accounting Association, Munich, Germany.

McMillan, E., \& Carlisle, Y. (2007). Strategy as order emerging from chaos: A public sector experience. Long Range Planning, 40, 574-593

Miles, M. B., \& Huberman, A. M. (1994). Qualitative data analysis. Newbury Park, CA: Sage.

Ortmann, G. (2010). On drifting rules and standards. Scandinavian Journal of Management, 26, 204-214.

Poston, R., \& Grabski, S. (2001). Financial impacts of enterprise resource planning implementations. International Journal of Accounting Information Systems, 2(4), 271-294.

Quattrone, P., \& Hopper, T. (2001). What does organizational change mean? Speculations on a taken for granted category. Mangement Acccounting Research, 12(4), 403-435.

Quattrone, P., \& Hopper, T. (2005). A time-space odyssey: Management control systems in two multinational organisations. Accounting, Organizations and Society, 30(7), 735-764.

Rigsrevisionen. (2005). Forsvarets ibrugtagning af it-systemet demars (sap).

Rom, A., \& Rohde, C. (2007). Management accounting and integrated information systems: A literature review. International Journal of Accounting Information Systems, 8(1), 40-68.

Scapens, R. W., \& Jazayeri, M. (2003). Erp systems and management accounting change: Opportunities or impacts? European accounting review, 12(1), 201-233.

Shaw, P., \& Stacey, R. D. (2006). The experience of risk, spontaneity and improvization in organizational change: Working live. London: Routledge.

Skærbæk, P. (2009). Public sector auditor identities in making efficiency auditable: The national audit office of denmark as independent auditor and modernizer. Accounting, Organizations and Society, 34(8), 971-987.

Skærbæk, P., \& Thorbjørnsen, S. R. (2007). The commodification of the danish defence and the troubled identities of its officers. Financial Accounting and Management, 23(3), 243-268.

Spathies, C., \& Ananiadis, J. (2005). Assessing the benefits of using an enterprise system in accounting information and management. Journal of Enterprise Information Management, 18(2), 195-210.

Stacey, R. D. (2007). Strategic management and organizational dynamics: The challenge of complexity. London: Prentice Hall.

Stacey, R. D. (2010). Complexity and organizational reality: Uncertainty and the need to rethink management after the collapse of investment banking. London: Routledge.

Stacey, R. D., \& Griffin, D. (Eds.). (2005). A complexity perspective on researching organizations: Taking experience seriously. London: Routledge.

Stacey, R. D., Griffin, D., \& Shaw, P. (2000). Complexity and management: Fad or radical challenge to systems thinking. London: Routledge.

Statsrevisoratet. (1999). Beretning om forsvarets forsyningsforvaltning. 
Statsrevisoratet. (2002). Beretning om forsvarets mål og rapportering vedrørende operativ kapacitet

Strauss, A., \& Corbin, J. (1998). Basics of qualitative research: Techniques and procedures for developing grounded theory. Thousand Oaks, CA: Sage.

Tangkjær, C. (2005). De mange ledelsesværktøjer: Hvor ligger ledelsens muligheder? Nordisk administrativt tidsskrift, 86(1), 95-106.

Thomas, R., \& Hardy, C. (2011). Reframing resistance to organizational change. Scandinavian Journal of Management, 27(3), 322-331.

Thorbjørnsen, S. (2007). Forsvaret i forandring : Et studie i officerers kapabiliteter under påvirkning af omverdenens forandringspres mod øget styring og læring. PhD Thesis, København.

Thorbjørnsen, S., \& Skærbæk, P. (2007). The commodification of the danish defence forces and the troubled identities of its officers. Financial accountability \& management in governments, public services, and charities, 23(3), 243.

Trott, P., \& Hoecht, A. (2004). Enterprise resource planning and the price of efficiency: The trade off between business efficiency and the innovative capability of firms. Technology Analysis \& Strategic Management, 16(3), 367-379.

van der Veeken, H. J. M., \& Wouters, M. J. F. (2002). Using accounting information systems by operations managers in a project company. Management Accounting Research, 13(3), 345-370.

Vogt, C. (2000). Intractable erp - a comprehensive analysis of failed enterprise resource planning projects. Software Engineering Notes, 27(2), 62-68.

Webster, J., \& Watson, R. T. (2002). Analyzing the past to prepare for the future: Writing a literature review. MIS Quarterly, 26(2), xiii-xxiii.

Yin, R. (2009). Case study research: Design and methods. Newbury Park, CA: Sage Publications. 